\title{
Interpretação em Libras e a mediação: um estudo de caso na pós-graduação
}

\author{
Libras interpretation and mediation: a post-graduate case study \\ Interpretación en Libras y mediación: un caso de estudio en estudios de posgrado
}

Recebido: 03/09/2021 | Revisado: 09/09/2021 | Aceito: 11/09/2021 | Publicado: 13/09/2021

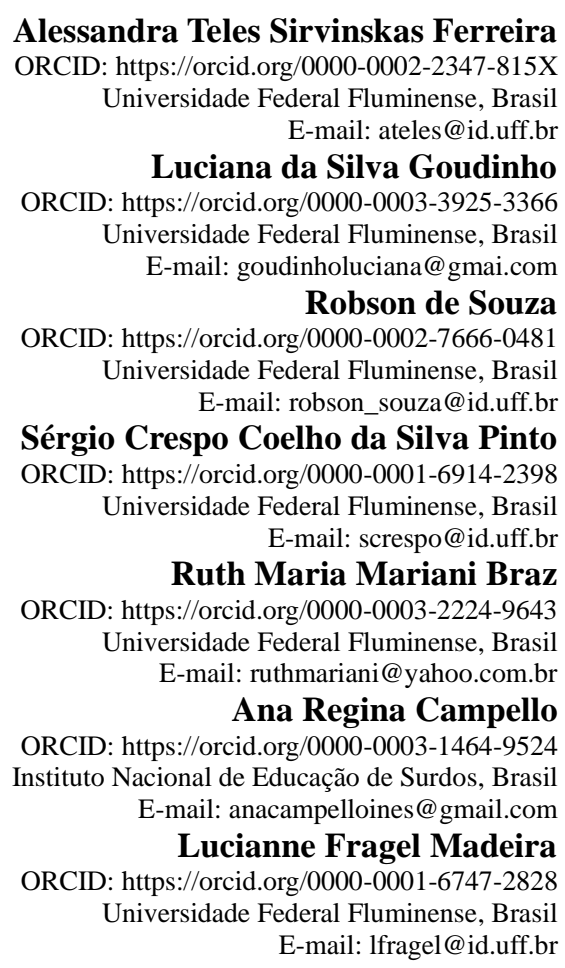

\section{Resumo}

A COVID-19 obrigou os docentes a fazerem uso das Tecnologias Digitais da Informação e Comunicação para promover o aprendizado de forma virtual. Este artigo é um estudo de caso sobre a complexidade entre interpretar as aulas e mediar o aprendizado, no modelo remoto de ensino, de uma discente surda, sinalizante, matriculada no curso de doutorado. O processo de mediação por meio da tradução e interpretação exigiu uma dinâmica diferenciada durante as aulas síncronas e assíncronas. Os dados deixaram lições como a necessidade de estratégias específicas para o ensino de surdos, equipamentos adequados, uma atuação do TILS que também medie a aprendizagem e a formação continuada dos profissionais.

Palavras-chave: COVID-19; Ensino remoto; Tecnologia.

\begin{abstract}
COVID-19 forced teachers to make use of Digital Information and Communication Technologies to promote learning in a virtual way. This article is a case study on the complexity between interpreting classes and mediating the learning, in the remote teaching model, of a deaf, who uses sign language student enrolled in the doctoral course. The mediation process through translation and interpretation required a whole different dynamic during synchronous and asynchronous classes. The data left lessons such as: the need for specific strategies for the teaching of deaf people, adequate equipment, a TILS performance that also mediates the learning and continuing training of professionals.
\end{abstract}

Keywords: COVID-19; Remote teaching; Technology.

\section{Resumen}

El COVID-19 obligó a los docentes a hacer uso de las Tecnologías Digitales de la Información y la Comunicación para promover el aprendizaje de manera virtual. Este artículo es un caso de estudio sobre la complejidad entre la interpretación de las clases y la mediación en el aprendizaje, en el modelo de enseñanza a distancia, de un estudiante sordo, quién utiliza el lenguaje de señas, matriculado en el curso de doctorado. El proceso de mediación a través de la traducción y la interpretación requería una dinámica diferenciada durante las clases sincrónicas y asincrónicas. Los 
datos dejaron lecciones como la necesidad de estrategias específicas para la enseñanza de los sordos, equipos adecuados, un rendimiento del TILS que también mide el aprendizaje y la formación continua de los profesionales.

Palabras clave: COVID-19; Enseñanza a distancia; Tecnología.

\section{Introdução}

No início de 2020, a Organização Mundial da Saúde (OMS) declarou haver uma pandemia causada pelo novo Coronavírus (SARS-COV-2). Com o intuito de resguardar vidas, medidas de segurança foram tomadas (MPT, 2020). Seguindo a orientação dada pela OMS, o Brasil adotou a quarentena em caráter temporário, com isso diversas empresas e escolas implementaram a proposta do trabalho remoto, por meio virtual.

As universidades não foram exceção. Os diversos cursos de ensino superior de modalidade presencial passaram a ser ministrados, em caráter excepcional, na modalidade de ensino remoto, em concordância com a Portaria MEC nº 343 e 345 de 2020 (Brasil, 2020a; Brasil, 2020b) e Resolução do Conselho de Ensino, Pesquisa e Extensão da Universidade Federal Fluminense - PROPPI/ UFF n. ${ }^{\circ}$ 157/2020 (PROPPI, 2020). Neste modelo, as disciplinas presenciais são substituídas por aulas que utilizem meios e tecnologias digitais de informação e comunicação, evitando o contato físico entre os alunos/professores/funcionários e, assim, contribuindo para a não propagação do vírus.

A universidade é um ambiente de formação e capacitação dos indivíduos para sua atuação profissional de forma competente, sendo assim, "o grande desafio posto para as universidades é formar educadores que não sejam apenas instrumentos de transmissão de conhecimentos, mas, sobretudo, de novas atitudes frente a diversidade humana” (Glat \& Pletsch, 2017, p. 4). Estabelecer discussões que permitam compreender a atuação do profissional Tradutor e Intérprete da Língua Brasileira de Sinais - Língua Portuguesa (TILS) e as limitações, necessidades e avanços na interação entre o TILS, o aluno surdo e os docentes, dentro deste contexto, poderá contribuir para uma melhor compreensão do papel educativo deste profissional e para a elaboração de estratégias, com o intuito de galgar maior qualidade no processo de ensino-aprendizagem dentro deste ambiente (Kelman, 2005; Guarinello et al., 2008; Lacerda \& Gurgel, 2011; Gomes \& Valadão, 2020).

Alunos, professores e demais profissionais, condicionados ao ensino/trabalho remoto, se encontram diante de um novo desafio. Todos habituados ao ensino/trabalho presencial se depararam com a necessidade de se adaptar à utilização de recursos tecnológicos e aos desafios de conseguir organizar um espaço dentro de seus lares para atuarem. Um profissional que antes da pandemia atuava em home office já tinha uma estrutura física, temporal e psicológica para isso, mas não foi essa realidade para a maioria dos profissionais.

Para a atuação do profissional TILS, esse modelo também tem seus impactos. No modelo presencial, há uma relação de troca e de cooperação entre os TILS, e também a colaboração dos discentes surdos na construção tradutória. Normalmente o trabalho é realizado em duplas, com revezamento combinado, no qual o profissional que estiver em descanso pode exercer a função de apoio sobre sinais ou expressões que melhor representem o que está sendo explanado. Em virtude da ampla diversidade das temáticas que são tratadas em cada disciplina acadêmica, a necessidade de um parceiro de trabalho é fundamental para situações como a falta de afinidade do TILS com a temática a ser tratada; a ausência de terminologias lexicais na língua de sinais para alguns termos e conceitos; a necessidade de explicações adicionais; e auxílio para realizar as escolhas tradutórias mais adequadas. Em alguns casos, o TILS recorre ao apoio do parceiro com o qual está atuando e, em outros casos, recorre à complementação ou combinação de termos junto ao(s) discente(s) surdo(s) (Gomes \& Valadão, 2020; Medeiros Portella et al., 2021).

No modelo de ensino remoto, muitas vezes, essa troca/cooperação não ocorre, pois, nas aulas, eventos e atividades síncronas, o TILS não visualiza o discente surdo nem visualiza o outro TILS, o que ocorre por uma série de motivos: as plataformas utilizadas não comportam várias câmeras ligadas ao mesmo tempo; quando é necessário compartilhar a tela com 
alguma apresentação, reduz a quantidade de câmeras que podem ficar abertas, as câmeras em destaque são apenas as que emitem som ou, ainda, porque a banda da internet não é boa, o que implica em problemas de vídeos travando e, com isso, exigindo que a haja menos câmeras habilitadas durante a aula. Enfim, as plataformas utilizadas ainda não oferecem recursos acessíveis suficientes para discentes surdos usuários da língua de sinais.

O último censo brasileiro, realizado em 2010, estimou que há um milhão de pessoas, com idade de até 19 anos, com alguma perda auditiva (IBGE, 2010). Segundo dados do Instituto Nacional de Estudos e Pesquisas Educacionais Anísio Teixeira (INEP, 2019), houve 6.569 de pessoas, com alguma deficiência auditiva, matriculadas em cursos de graduação no ano de 2019. Se considerarmos a idade destas pessoas da pesquisa de 2010, hoje, podemos dizer que estariam com 31 anos, sendo, portanto, potenciais candidatos aos cursos de mestrado e doutorado. Em 4 anos, os ingressantes do ano de 2019 também serão fortes candidatos aos cursos de pós-graduação lato sensu e stricto sensu.

Com isso, as universidades precisam estar cada vez mais preparadas para receber estes alunos em potencial, capacitando seus professores, garantindo a presença de profissionais TILS para promover a acessibilidade, adaptando sua estrutura e seus materiais para que estejam acessíveis a este público.

A profissão do TILS, no nível superior, ainda é bem recente no Brasil. Data de 2008 o primeiro curso aberto para este fim, na Universidade Federal de Santa Catarina. Em 2014, outras seis universidades abriram o curso de bacharelado para formar estes profissionais (Quadros \& Stumpf, 2014). A corrida para capacitar estes profissionais se deu a partir do Decreto 5.626/05 (Brasil, 2005), o qual determinou a formação de TILS em nível superior. Somente em 2010, com a Lei 12.319/10 (Brasil, 2010), houve a regulamentação da profissão. Dentro deste cenário, encontramos profissionais se adequando a novas realidades de interpretação, no ambiente universitário, muitas vezes sem ao menos possuir qualquer formação de nível superior (Lacerda \& Gurgel, 2011).

Soma-se a este cenário a atual conjuntura mundial da pandemia da COVID-19, que obrigou os docentes a fazerem uso de novas tecnologias para promover o aprendizado de forma virtual. Este desafio torna-se, todavia, ainda mais complexo quando alunos surdos fazem parte da turma. Atuar para que o discente surdo possa ter acesso aos conteúdos e às discussões é um ato inclusivo necessário tanto no contexto educacional quanto no mundo contemporâneo.

As mídias digitais passaram a ser o veículo principal de ensino. As plataformas de sala de aula e as videoconferências se tornaram os ambientes educacionais. Aos professores coube a tarefa de aprender a manusear tais ferramentas e encontrar um meio de garantir o ensino do conteúdo, buscando se adaptar à nova realidade.

O processo de adaptação foi e tem sido experimental, na base da tentativa e erro. Os ajustes são realizados e, gradativamente, ambos, docentes e discentes, vão se ajustando. Para os alunos surdos há ainda a necessidade de um terceiro indivíduo, o TILS, que também precisou se ajustar a esta nova situação.

A atuação do TILS requer as capacidades de receber e identificar a mensagem, reconhecer o contexto, reter a mensagem na memória de curto prazo, reconhecer a intenção semântica, estabelecer a equivalência semântica (fazer escolhas lexicais apropriadas para a língua alvo) para então, realizar a interpretação (Nascimento \& Segala, 2018; Medeiros Portella et al., 2021).

No ambiente virtual, os problemas causados pela falta de conexão de qualidade atrapalham tanto o TILS a compreender o que foi dito quanto o discente surdo, que, por vezes, não visualiza de forma clara o intérprete. Há, ainda, a necessidade de lidar com as diferentes plataformas de videoconferência, que oferecem formas diversas de posicionamento dos participantes. Há plataformas que permitem fixar uma pessoa na tela; outras em que as pessoas mudam de posição sempre que alguém entra ou sai da sala; outras em que a pessoa que fala aparece em tamanho maior na tela principal e quem não fala some da tela; outras em que, ao compartilhar a tela para a apresentação dos slides do professor, por exemplo, os demais participantes somem ou ficam muito pequenos e, caso o aluno opte por fixar a imagem do TILS, deixa de ver o que está sendo 
compartilhado. Mais um ponto importante a ser destacado é em relação à posição ideal do celular para a transmissão da imagem do TILS, que é na horizontal, pois quando posicionado na vertical há cortes na imagem e perdas na sinalização. Diante das situações descritas, o docente, o TILS e o aluno precisam se adaptar e encontrar soluções para esses desafios.

\subsection{TILS e/ou Mediador no Ensino Superior}

Com a Lei Brasileira de Inclusão - LBI (Brasil, 2015), a inclusão vem sendo implementada gradativamente, mas o objetivo é que ela alcance todos os indivíduos contemplados na legislação. Sendo assim, muitos surdos têm sido matriculados em escolas regulares e, de acordo com a lei, devem ter um TILS para garantir sua acessibilidade.

O reconhecimento da Língua Brasileira de Sinais (Libras) como meio legal de comunicação e expressão das comunidades surdas brasileiras, no ano de 2002, trouxe como consequência a garantia do direito à acessibilidade linguística em diversos ambientes, bem como o reconhecimento da língua de sinais como meio adequado para o desenvolvimento subjetivo e cognitivo do surdo e o direito de acesso aos conteúdos por meio da Libras e de se expressar e registrar o seu conhecimento nesta língua.

Para promover tal acessibilidade, um profissional essencial tem sido o TILS. Na década de 80, no Brasil, iniciaram-se os trabalhos com TILS, de maneira informal, principalmente em ambientes religiosos e informais. Após discussões em congressos internacionais, em 1987, na Finlândia, e em 1995, na Áustria, ficou evidente a importância da formação desses profissionais (Guarinello et al., 2008).

No Brasil, o Decreto $\mathrm{n}^{\mathrm{o}}$ 5.626/05 (Brasil, 2005) marcou o reconhecimento do profissional TILS a partir do estabelecimento dos critérios de formação em cursos de nível superior ou cursos reconhecidos por instituições de nível superior devidamente registradas. Todavia, a baixa remuneração e a concentração dos cursos de formação nas grandes metrópoles trazem como consequência um número limitado de profissionais devidamente formados e capacitados para atender à demanda existente (Martins, 2003).

O TILS contribui para reduzir as dificuldades encontradas pelo surdo diante da barreira linguística. Interpretar envolve conhecimento de ambas as línguas: a língua fonte e a língua para a qual será realizada a tradução. Além disso, o conhecimento do conteúdo a ser traduzido/interpretado é importante para que possa encontrar o termo equivalente adequado ao contexto (Gomes \& Valadão, 2020; Medeiros Portella et al., 2021).

O papel do TILS no ambiente escolar é muito discutido. Kelman (2005), em suas pesquisas sobre o papel do TILS em uma sala de aula, identificou diversos papéis desempenhados por este profissional: tutor de língua portuguesa, tutor de língua de sinais, mediador que ajusta o currículo, orientador de trabalhos e exercícios, TILS entre alunos, tutor de organização acadêmica, coprodutor pedagógico a partir das discussões desenvolvidas junto ao professor da disciplina. Cabe aqui destacar que o intérprete pode ser visto como mediador por atuar como aquele que media as partes de forma imparcial, ele está no meio do processo, ele atua mediando a língua. No entanto, quando nos referimos a mediador aqui, vamos além da mediação linguística, utilizamos este termo com o mesmo sentido de mediador escolar, o qual tem a função de explicador, orientador, de ajustar o currículo às especificidades do seu aluno, auxiliando no processo de aprendizagem (Mousinho et al., 2010). Assim podemos perceber a importância da presença desse profissional no ambiente escolar, e não apenas no momento da aula.

De acordo com Almeida (2017), é no diálogo e na interação com o outro que o aprendizado é estimulado, esse outro podendo ser, inclusive, o TILS enquanto mediador. É muito comum que o aluno surdo não disponha de um grupo de colegas de turma com os quais consiga trocar/interagir acerca dos conteúdos em virtude da barreira linguística. Essa troca é fundamental para o desenvolvimento cognitivo e cultural do indivíduo. Embora haja grande discussão quanto a este não ser o 
papel do TILS, ao ceder e estabelecer esta interação com o aluno, o TILS pode estar contribuindo com o desenvolvimento psicológico e pedagógico do indivíduo (Vygotsky, 1995).

Todavia, a presença do TILS não é garantia total de inclusão e de acessibilidade. Não basta apenas a tradução no momento das aulas, outras ações devem ser levadas em consideração, como nível linguístico dos alunos; oferta de aulas de língua de sinais para toda a comunidade escolar, preferencialmente ministrada por instrutor surdo; metodologias que priorizem o uso de imagens; estratégias pedagógicas que prezam pela especificidade do aluno; organização do espaço de aula que facilite a visualização dos demais colegas, do professor e do TILS pelo discente surdo; disponibilização de material didático bilíngue; espaços de trocas entre alunos; momentos de interação entre professor e TILS para criar estratégias adequadas de ensino e de abordagem da temática a ser trabalhada e esclarecer dúvidas do TILS sobre o conteúdo (Guarinello et al., 2008).

Um dos grandes desafios lançados pela profissão é o conhecimento aprofundado em relação ao funcionamento de ambas as línguas e de estratégias que auxiliem no ato da tradução/interpretação de modo a garantir o máximo possível de clareza e fidelidade (Xavier, 2012; Medeiros Portella et al., 2021). A língua não é linear, não se trata de traduzir termo a termo. O processo tradutório ocorre considerando o contexto e é influenciado pelo nível de conhecimento e o tempo de experiência do TILS. Quando o TILS não domina o tema/assunto a ser interpretado, podem ocorrer supressões, adições ou mesmo confusão, privando o surdo do conteúdo completo expresso naquele contexto (Guarinello et al., 2008; Gomes \& Valadão, 2020).

No ensino superior, um dos maiores desafios enfrentados pelo TILS é a falta de léxicos, oficializados pela comunidade acadêmica surda, correspondentes aos termos técnicos e teóricos utilizados nas aulas. Por conta dessa carência, uma das principais estratégias utilizadas pelos TILS é a datilologia, escrever a palavra através do alfabeto manual que segundo Cordeiro (2019, p. 40) "equivale ao significado de soletração”, para referenciar o termo sem sinal, todavia essa estratégia só é funcional se o aluno surdo já tiver domínio do significado da palavra, caso contrário, o aluno não terá acesso à informação de forma completa.

Outro desafio encontrado é falta de acesso prévio ao conteúdo que será abordado no momento da atuação, prejudicando o processo interpretativo, isso porque não há como o TILS conhecer todos os sinais referentes a diferentes conteúdos e áreas (Guarinello et al., 2008; Gomes \& Valadão, 2020; Medeiros Portella et al., 2021). Ao ter acesso com antecedência ao conteúdo e esclarecer dúvidas com o professor da disciplina, o TILS pode pesquisar sinais da área de conhecimento referente ao material, bem como estar preparado para utilizar as estratégias necessárias para oferecer uma interpretação adequada, possibilitando uma aula realmente acessível.

Vale ressaltar que, no contexto aqui analisado, os TILS desempenharam também diferentes papéis de mediação. Por vezes pedagógica, entre a Discente Surda (DS) e os conteúdos desenvolvidos nas disciplinas; por vezes social, entre a aluna e os demais colegas ouvintes ou entre o aluno e os professores. Assim, como esclarece Xavier (2012), o intérprete que atua no contexto educacional "encontra-se extremamente imbricado no processo de mediação social e pedagógica que perpassa o sujeito surdo" (Xavier, 2012, p. 60).

O objetivo deste artigo é discutir os desafios encontrados durante o processo de tradução e interpretação da Libras dentro do contexto da pós-graduação através de um estudo de caso em turma de doutoramento, além de destacar as dificuldades metodológicas, pedagógicas e tecnológicas enfrentadas, de forma a elencar alternativas que possam auxiliar os profissionais Tradutores e Intérpretes de Língua de Sinais - Língua Portuguesa (TILS) durante suas atividades acadêmicas, principalmente em relação às atividades remotas.

\section{Metodologia}

Esta é uma pesquisa participante de um estudo de caso. Participante porque há a inserção do pesquisador no campo de investigação, de forma próxima ou distante, sendo não apenas um observador mas também um informante, colaborador e/ou 
interlocutor (Brandão, 1999). Neste tipo de pesquisa, conforme o pesquisador pesquisa como um sujeito ativo, ele reflete sobre sua prática, sobre o seu objeto de pesquisa, se educa, e se organiza para produzir uma ação construída coletivamente (Brandão, 1999).

A investigação realizada tem um caráter de um estudo de caso, um método que coleta dados de eventos reais e tem como objetivo descrever, explorar e/ou explicar fenômenos atuais dentro de um contexto (Eisenhardt, 1989; Yin, 2003). Para isso, foi utilizada uma abordagem qualitativa que prima pela compreensão, descrição e explanação de questões relacionadas a indivíduos e espaço(s) (Minayo, 2001; Prodanov \& Freitas, 2013). Aqui foi relacionada a atuação de três TILS, que são os pesquisadores participantes, para uma DS, cursando o doutorado na Universidade Federal Fluminense (UFF).

\subsection{Sujeitos da Pesquisa}

O processo utilizado envolveu três alunos ouvintes, do mesmo curso, profissionais atuantes na educação de surdos, fluentes e certificados em interpretação e tradução da Libras e uma DS sinalizante, todos matriculados na disciplina "Tópicos em Ciências, Tecnologias e Inclusão", cursada no segundo semestre letivo de 2020 na modalidade ensino remoto. Vale ressaltar que a atuação destes alunos se deu de maneira voluntária e colaborativa, na disciplina referida acima e nas demais em que a DS estava inscrita, para suprir uma falta de profissionais na instituição. Nos referimos aos três alunos como TILS pela característica da sua atuação principal. Para que os alunos TILS não fossem prejudicados, todas as aulas foram gravadas e disponibilizadas. Os professores também se dispuseram a esclarecer quaisquer dúvidas que pudessem surgir posteriormente, já que, durante as aulas, os alunos TILS estariam com sua atenção focada na interpretação e tradução.

\subsection{Instrumentos}

Devido à necessidade de realização das aulas na modalidade remota, algumas ferramentas tecnológicas foram utilizadas pela DS e pelos TILS, dentre elas destacamos:

- Funcionalidade do Meet - legenda em língua portuguesa;

- Webcaptioner';

- Chamadas de vídeos através do smartphone;

- Mais de um aparelho simultaneamente para ampliar a imagem do TILS.

A principal forma de acesso às aulas e aos conteúdos, no formato remoto, foi a utilização de ferramentas do pacote $\mathrm{G}$ Suite, do Google, até pelo fato de os e-mails dos alunos serem institucionais e vinculados ao Gmail. As aulas síncronas aconteceram por meio do Google Meet, plataforma que exibe telas simultâneas para a interação entre professores e alunos e permite fixar a tela para acompanhar a tradução para a Libras. Uma funcionalidade deste aplicativo que possibilita encontros remotos é a legendagem. O recurso pode ser ativado ou desativado ao selecionarmos opções nas configurações do Meet e foi utilizado pela DS como mais um suporte ao entendimento das informações orais que eram convertidas em texto.

Em alguns encontros, a ferramenta utilizada foi o $\mathrm{IMO}^{2}$, um aplicativo de videochamada utilizável em smartphones ou computadores. A grande diferença estava na utilização do smartphone ao lado da tela do notebook, para visualizar o professor numa tela e o tradutor na outra. A utilização de duas janelas do navegador, com o professor ou a apresentação fixada numa das janelas e o tradutor na outra, possibilitou a ampliação das janelas de visualização e foi um formato sugerido com a finalidade de, ao utilizar um gravador de tela, capturar as imagens projetadas ao mesmo tempo.

\footnotetext{
${ }^{1}$ https://webcaptioner.com/

2 https://shortest.link/XQ3
} 
Para eventos externos, divulgados no grupo de Whatsapp, foi sugerida a utilização de um transcritor de áudio on-line e gratuito. O Webcaptioner captura o áudio do microfone e converte em texto. Embora não apresente o texto com formatação ou pontuação, foi visto pela DS como uma possibilidade de aprimorar o aprendizado da língua portuguesa.

Para a coleta de dados, foram elaborados dois questionários ${ }^{3}$, no Google Forms, contendo quatro perguntas fechadas em ambos os questionários, dez perguntas abertas no questionário para os TILS e treze perguntas abertas no questionário para a DS. Os questionários, junto com o termo de consentimento livre e esclarecido, foram enviados via e-mail e via WhatsApp, entre março e abril de 2021.

\section{Resultados e Discussão}

Entre os três TILS que participaram do presente estudo, dois são do sexo feminino, com idades de 35 e 37 anos, e um do sexo masculino, com 49 anos de idade. A DS é do sexo feminino e tem 54 anos.

Quanto à formação dos participantes, observa-se que os TILS são formados em cursos da área educacional (Licenciatura em Educação Física, Letras e Pedagogia), possuem mestrado com enfoque educacional também (Diversidade e Inclusão, Teorias Literárias e Educação). A DS também tem sua formação toda voltada para a área educacional: é pedagoga e mestre em diversidade e inclusão. O fato de terem uma formação similar colaborou no processo de explicação e de compreensão daquilo que está sendo tratado nas aulas.

Apesar de a similaridade contribuir neste processo, o fato de tanto os TILS como a DS serem alunos do mesmo curso, no mesmo período, há questões que ainda estão sendo aprendidas por eles, conhecimentos sobre os quais não possuem domínio. A DS relata exatamente isso em sua fala:

Então, o problema é que o intérprete não tem o conhecimento sobre um determinado termo, palavra ou conceito. Se o intérprete não tiver entendido muito bem o que o professor disse, ele não conseguirá me passar com clareza e eu também não compreenderei muito bem, igual ao intérprete. Também ocorrem problemas quando há leitura de algum texto e, por falta de contexto, o intérprete, às vezes, se sente inseguro ou mesmo não sabe como sinalizar determinada palavra, por vezes exige uma pesquisa sobre o termo, ou fazer uma rápida leitura do texto ou perguntar ao professor posteriormente. Esse processo aumenta a duração das aulas, não se trata de algo a ser ensinado apenas no ambiente de sala de aula. (resposta da DS à questão 8)

Um TILS sinaliza a mesma dificuldade apontada pela DS, menciona o desafio de interpretar diante do vocabulário rebuscado utilizado no meio acadêmico, vocabulário este que não é utilizado cotidianamente e que demanda uma pesquisa, por parte do TILS, para poder se apropriar deste vocabulário. Outra dificuldade apontada pelos TILS foi a de não haver uma disponibilização prévia do conteúdo:

Das quatro disciplinas nas quais interpretamos, apenas um docente se dispôs e se organizou uma vez para nos mostrar o conteúdo. Todavia esse compartilhamento de conteúdo ocorreu apenas minutos antes do início da aula, o que não contribui muito com o trabalho interpretativo por não nos permitir uma pesquisa por sinais. Os demais docentes não demonstraram tal preocupação em compartilhar o conteúdo. (resposta do TILS 1 à questão 7)

Apesar da formação semelhante à da DS e de estarem no mesmo curso, a agilidade no processo tradutório é afetada pela falta do conhecimento específico do tema ou assunto tratado nas aulas (Napier, 2002). Observa-se, na trajetória profissional dos três TILS, experiências em escolas de educação básica, da educação infantil ao ensino médio; apenas um, dentre os três TILS, relatou ter experiência de interpretação em ambiente universitário.

\footnotetext{
${ }^{3}$ https://shortest.link/VYe
} 
A falta do domínio do conteúdo a ser tratado é algo que nos leva a refletir sobre os profissionais tradutores e intérpretes presentes no ensino superior. Em muitas universidades públicas, a contratação dos TILS é composta por uma série de procedimentos burocráticos, dependem da criação dos cargos na instituição, da abertura de concursos públicos. Por vezes, o que se vê são contratações temporárias de dois anos de atuação, as quais não podem ser renovadas consecutivamente e, na maioria dos casos, utilizam apenas etapas teóricas na modalidade escrita, quando uma etapa seletiva prática seria fundamental para esse tipo de cargo. Essa descontinuidade na atuação do profissional acarreta perdas, pois todo o conhecimento adquirido e desenvolvido ao longo dos dois anos de atuação precisará ser iniciado pelo novo TILS contratado (Lacerda \& Gurgel, 2011).

Além desta perda, há a demora nas contratações. Muitas vezes o aluno surdo se encontra no ambiente e precisa fazer leitura labial, ou utilizar softwares para legendar a fala do professor e, como sabemos, estes softwares não são muito precisos, a legenda não fica perfeita. Soma-se a isso a dificuldade com a língua portuguesa de muitas pessoas surdas. Como consequência, a dificuldade em acompanhar a aula só aumenta, como podemos perceber no relato da DS a seguir, que explica sobre diferentes fases do seu processo de aprendizagem e as estratégias utilizadas:

$\mathrm{Na}$ verdade, é um problema do meu desenvolvimento linguístico. Isso porque eu, dos 2 anos e meio de idade até os 12 anos, neste período eu perdi a linguagem, também perdi informação. Eu cresci em uma escola sem acessibilidade em Libras. Eu estudei em uma escola de ouvintes do $1^{\circ}$ ao $5^{\circ}$ ano, antigamente era $1^{\text {a }}$ a $4^{\mathrm{a}}$ série, não havia acessibilidade em Libras, o que me fazia perder informações. Posteriormente me mudei para o Rio de Janeiro e fui estudar no INOSEL (Instituto Nossa Senhora de Lourdes), na Gávea. Cursei ali da $5^{\mathrm{a}}$ a $8^{\mathrm{a}}$ série. Depois de me formar ali, ingressei no Liceu de Artes e Ofícios, no Rio, onde cursei o ensino médio. Nunca teve intérprete, eu não recebia informação. Então não adquiri conhecimento, perdi muito conteúdo. Então, quando entrei na faculdade, eu não compreendia diversas coisas, por causa deste longo período em que perdi informações/conteúdo. Ao entrar na faculdade foi mais difícil. Tinha intérprete, eu mesma que paguei o profissional, porque antigamente não havia a obrigatoriedade de ofertar a acessibilidade em Libras dentro da faculdade/ensino superior. Mas a faculdade me deu $50 \%$ de desconto nas mensalidades. Portanto, na graduação o problema não era apenas do intérprete, era meu também. Era um problema para os dois lados. Eu fiz muito esforço em buscar o conhecimento. Antigamente, em 1996, não tinha internet, Facebook, redes sociais como hoje, isso surgiu depois. Eu me esforçava em manter a atenção na intérprete, que não possuía formação universitária, ela tinha formação de ensino médio, igual a mim. Ela tinha um conhecimento do curso dela em Enfermagem, cuja linguagem é outra. Eu entrei na faculdade de Pedagogia e a intérprete não tinha conhecimento da área de educação. Ela teve muita dificuldade. Em 1996 eram raros os intérpretes nas faculdades, muito raro. Em Porto Alegre até já tinha, mas aqui no Rio, eram poucos e espalhados. (resposta da DS à questão 6)

Preciso marcar outro dia, preciso que haja uma explicação, só eu e o intérprete, me explicando aos poucos o texto até que fique claro e eu consiga entender. Isso é importante... Percebo que não apenas eu, mas vários outros surdos, às vezes com português inferior ao meu, têm muitas dificuldades. Outros com português perfeito, muito melhores do que eu que conseguem um bom desenvolvimento. Mas, isso depende do histórico educacional. (resposta da DS à questão 8)

$\mathrm{Na}$ resposta da DS, verificamos o papel do TILS ultrapassando o ambiente de sala de aula, atuando como um mediador, um tutor. Não está apenas traduzindo o texto ou a aula, mas explicando, trabalhando o texto com a DS para melhor esclarecer termos, palavras e contexto.

Em relação ao entendimento do papel do intérprete e do mediador, verificamos que tanto os TILS quanto a DS entendem que a função do intérprete envolve a parte do discurso, a transmissão de informações de uma língua para a outra, realizada de forma neutra, em que a relação com o discente surdo se encerra junto com a aula. Já a função do mediador foi vista como a de um facilitador da aprendizagem que envolve o diálogo explicativo ao longo da aula e após a aula com o discente surdo, bem como a busca de soluções e/ou adaptações que visem contribuir com a melhor compreensão do conteúdo pelo discente surdo, como veremos nos relatos a seguir:

O mediador tem um papel de esclarecer, de contribuir para a compreensão, de identificar as dificuldades e buscar meios ou adaptações para sanar essas dificuldades. O trabalho do mediador não se encerra com o fim da aula, o 
mediador dialoga com o aluno, responde seus questionamentos e, caso não saiba responder, busca ou orienta sobre como buscar estas respostas. Também procura soluções para que o aluno veja melhor a aula e passa suas percepções e sugestões para o docente, visando o melhor atendimento ao aluno mediado. (resposta do TILS 1 à questão 12)

O intérprete recebe a informação e passa em Libras. O mediador recebe a informação e ajuda explicando. Eu prefiro assim, como mediador. O intérprete tem uma relação fria, apenas de passar a informação. Se um intérprete é bem próximo ou tem, na família, algum parente surdo, ou tem contato direto com pessoas surdas. Igual a Luciana, a Alessandra ou o Robson que tem filho surdo. Alessandra e Luciana têm contato com surdo, contato com Libras. Não só com alunos, mas também com amigos fora da escola e também são profissionais éticos. Porque estas pessoas têm a preocupação com o aluno surdo, se entendeu bem, se compreendeu a explicação. O profissional intérprete não tem essa preocupação, ele está fazendo o trabalho dele, interpreta e quando acaba a aula ele vai embora sem se preocupar em saber se você entendeu ou não. O intérprete "familiarizado" pergunta: Você entendeu? Não? Depois da aula a gente se encontra de novo para eu poder te explicar, no privado, só nós dois. Depois nos encontramos no privado, por vídeo mesmo, e ocorre a explicação detalhada com exemplos. Trata-se de um apoio, não é uma dependência, não se trata de achar que o discente é inferior ou um coitado. Não. É uma preocupação saber se o discente de fato entendeu o que foi dito e estudado. Porque não adianta só interpretar, friamente, e o aluno não entender nada. Assim não precisa de intérprete. Eu penso assim. Não adianta. (resposta da DS à questão 15)

A DS relata ser mais interessante ter um mediador que domine Libras do que apenas um intérprete que passe os conteúdos e que, ao terminar a aula, vai embora. Ela destaca a importância do apoio após as aulas para melhor compreensão do conteúdo tratado. Ressalta que os três TILS, no doutorado, apresentaram esta preocupação em perguntar se havia compreendido o que foi dito ou se tinha dúvidas e se disponibilizaram a realizar um diálogo após as aulas. Ela define essa relação como mais próxima, mais familiar, e afirma que a troca a fazia sentir-se bem.

Os TILS relatam que a relação com a DS foi colaborativa. Um TILS relatou o sentimento de insegurança, em alguns momentos da interpretação, pela falta do contato visual com outro TILS ou mesmo porque a DS estava com a câmera fechada, pois buscava algum apoio para alguns sinais ou para saber se a DS entendeu ao olhar para ela. Observamos que a atuação destes profissionais está diretamente ligada ao entendimento pelo discente surdo, há uma preocupação em saber se estão sendo entendidos, se estão usando os sinais que melhor atendem ao interlocutor.

Carl Rogers falava que a empatia tem um importante papel no processo de aprendizagem. A atuação neutra e distante pode comprometer a assimilação pelo aluno (Zimring, 2010). A demonstração de cuidado, a preocupação em se fazer entender e a disponibilidade em se colocar no lugar do outro são importantes não apenas no aspecto emocional, mas também no cognitivo.

A formação e a experiência do intérprete são fundamentais. Sua área de conhecimento, seu contato e sua relação com os surdos interferem na qualidade do serviço prestado. Os TILS afirmam ter conhecimento de Libras há 13, 20 e 24 anos. Dentre os três TILS, um afirmou atuar no ambiente religioso além da escola; outro afirmou atuar em salas de recursos e como professora em sala bilíngue; e o terceiro afirmou ser pai de surdo, atuar como TILS, professor bilíngue em sala de aula e em sala de recursos.

A DS afirmou que conhece e usa Libras há 42 anos, tendo aprendido no INOSEL, escola a qual frequentou a partir da $5^{\mathrm{a}}$ série. Ao longo de sua trajetória escolar, teve contato com diversos profissionais com domínio de Libras. Ela observa que os intérpretes que têm contato dentro da família ou convivem com os surdos de forma regular preocupam-se com a compreensão do que é traduzido para o surdo. Também enfatizou a importância de dois dos TILS terem formação em nível de mestrado na mesma área que a dela, de forma que o conhecimento da área, dominado por estes profissionais, permitiu melhores correlações com a informação apresentada pelos professores e, consequentemente, uma interpretação mais coerente. Relatou, ainda, que houve encontros com os TILS após algumas aulas para obter maiores esclarecimentos.

Todos os TILS afirmam que consideram importante buscar melhorar o próprio desempenho na interpretação, entendendo ser necessário ampliar o vocabulário, buscar cursos para aprofundar o conhecimento da Libras e ter em mente que 
a Libras é uma língua viva e dinâmica, que apresenta variações e mudanças como as demais línguas; por isso, buscar atualização e aperfeiçoamento constantemente é fundamental para garantir uma interpretação/tradução de qualidade.

Além da formação e capacitação do intérprete, é preciso considerar a trajetória de vida do aluno surdo. A falta de intérpretes ao longo do ensino básico da DS influenciou no processo de aprendizagem no ensino superior. Houve uma necessidade de maior esforço por parte dela para conseguir acompanhar os conteúdos e assimilar o que estava sendo ensinado, como já descrito anteriormente por ela.

Uma TILS relata a preocupação com os termos acadêmicos ao responder ao questionário, indicando o cuidado que tem ao observar o nível do vocabulário do seu discente surdo para que possa melhor se adequar a este e passar a informação, aproveitando ao máximo o que o aluno já domina para melhor atendê-lo. Outro TILS apontou o estudo prévio do conteúdo, sempre que possível, para poder explicar melhor o que será interpretado.

Procuro adequar a tradução/interpretação ao nível linguístico do aluno. Por exemplo, se o aluno surdo consegue fazer leitura labial eu uso como estratégia de apoio; se o aluno está iniciando o aprendizado na Libras eu uso uma sinalização mais lenta com apoio de imagens e classificadores; se o aluno é fluente a sinalização segue naturalmente. (resposta do TILS 2 à questão 6)

Tradução simultânea e consecutiva; Estudo prévio, sempre que possível; Uso de equivalentes culturais para expressões idiomáticas; Atuação conjunta para versão sinalizada e versão voz. (resposta do TILS 3 à questão 6)

A DS também aponta o acesso do TILS ao conteúdo com antecedência como fator importante para melhorar a interpretação. Além disso, enfatiza que é importante estabelecer critérios sobre o perfil adequado do profissional para atuar em cada nível de ensino, pois a formação adequada, com conhecimento da área na qual interpretará, resulta em uma interpretação/tradução mais precisa.

O processo de estudo prévio do conteúdo perpassa pela relação entre TILS e o docente. Há a necessidade do diálogo e do envio antecipado do conteúdo que será abordado na aula. Nos relatos, os TILS apontaram que os docentes não compartilhavam o conteúdo com antecedência, mas eram solícitos às intervenções e interações dos TILS e da DS durante as aulas. Também identificaram a necessidade de orientar os docentes quanto à conduta diante da presença de uma DS na sala de aula remota. Para isso, os TILS elaboraram um guia com orientações para o incentivo a práticas inclusivas durante as atividades síncronas.

Esta iniciativa dos TILS revela uma lacuna existente na formação de docentes em todos os níveis de ensino. O objetivo foi incentivar atitudes que poderiam contribuir para a compreensão e/ou clareza daquilo que estava sendo ensinado. Uma das ênfases dada pelos TILS foi a necessidade de ser feita uma pausa na fala no momento da apresentação de uma imagem ou, ainda melhor, fazer a descrição da imagem, tendo em mente que o surdo precisa olhar o intérprete para acompanhar a explicação; se a imagem apresentada é o foco da fala, ela deve ser observada e compreendida pelo surdo também. O material utilizado pelo docente deve ser sempre inclusivo, contendo descrições que permitam a melhor compreensão e o enriquecimento do conteúdo ou conceitos a serem repassados.

Um destaque dado pela DS foi a duração das aulas, longas horas de aula sem intervalo, o que é muito cansativo para a vista, afinal, como surda, ela precisa olhar direto para a tela para visualizar o intérprete. Ela relata que houve ocasiões em que teve de ficar 3 horas ou mais olhando para a tela e, por vezes, houve disciplinas que eram seguidas, o que implicava em mais horas de interação com a tela. Como consequência, houve perda de informações e do conteúdo por conta do cansaço e da dificuldade em se concentrar por tanto tempo. Uma solução, vivenciada pela DS, em outras universidades, e que a agradou muito, foi o intervalo de 20 minutos a cada 30 minutos de aula. Para ela, esse intervalo se revelou muito produtivo, pois ajudou a descansar a vista e a mente, o que possibilitou recuperar a atenção ao retornar e, com isso, melhorou a compreensão do 
conteúdo ensinado. De posse deste feedback da aluna, esta foi mais uma orientação/sugestão apresentada aos docentes do curso.

Quanto aos aspectos positivos do ensino remoto, podemos elencar os seguintes, apontados pelos TILS:

1. facilidade de estar em aulas sem a necessidade de deslocamento;

2. otimização do tempo;

3. menor gasto financeiro por não precisar se deslocar nem se alimentar fora de casa;

4. facilidade em pesquisar sinais no computador durante o revezamento de intérpretes;

5. possibilidade de gravar as aulas e sua interpretação para poder identificar suas falhas e melhorar seu desempenho;

6. fato de haver menos interações simultâneas no ambiente virtual, o que facilita a tradução.

De negativo, os TILS pontuaram:

1. problemas de conectividade da internet, o que gera perda de informação ou imagem travando o que torna mais cansativo para o discente surdo acompanhar a aula;

2. impossibilidade de ver os demais intérpretes para buscar apoio no momento de dúvida sobre algum sinal;

3. impossibilidade de observar se a interpretação está sendo compreendida nos momentos em que o discente surdo mantém a câmera desligada;

4. necessidade de diversos equipamentos de boa qualidade para garantir uma imagem mais nítida do intérprete;

5. conflitos para elementos e/ou imagens que necessitam parar de ser transmitidos a fim de que a aluna pudesse realizar a sua anotação sobre a disciplina ministrada;

6. leitura rápida, pelos professores, de alguns trechos para fazer observações acerca deles posteriormente.

A possibilidade de estar em diversos lugares sem a necessidade de deslocamento ou gastos financeiros apontada como positiva pelos TILS é um fator importante a ser observado pelas instituições quando do retorno às atividades presenciais. Isso porque, de acordo com as pesquisas realizadas por Lacerda e Gurgel (2011), o TILS costuma atuar em vários lugares, exigindo que se desloque constantemente e causando desgaste físico e emocional (estresse no trânsito, preocupação com o horário, estresse pelo excesso de informações na mente), o que pode interferir na sua atuação profissional.

$\mathrm{O}$ fato de estes profissionais terem o interesse e o cuidado em assistir ao seu desempenho durante a interpretação para buscar melhorias também é um fator interessante. Assistir a si mesmo e avaliar suas escolhas tradutórias podem contribuir para uma melhor atuação.

Diante das dificuldades elencadas, os TILS consideram que o seu desempenho poderia ser melhorado ao atentarem para as questões de formação pessoal, necessidades técnicas e melhoria de alguns recursos virtuais.

No quesito formação pessoal, citam a realização de cursos de capacitação para aperfeiçoar as escolhas tradutórias, assistir à atuação dos demais TILS e atuar mais neste nível de ensino para internalizar o vocabulário próprio deste ambiente. Esta percepção dos TILS pode ser ratificada nas pesquisas realizadas por Lacerda e Gurgel (2011), nas quais afirmam que os cursos de capacitação contribuem para uma reflexão sobre a língua, suas características e aspectos, dados importantes para a atuação do profissional. Afirmam ainda que a experiência profissional dentro de determinado nível de ensino é fundamental para a apropriação da linguagem específica pelo TILS. O aperfeiçoamento, o conhecimento de novas técnicas e a maior apropriação da língua podem ocorrer através de formação continuada. Não basta apenas o convívio com pessoas usuárias da língua; o estudo específico e aprofundado é essencial para o bom desempenho do profissional TILS. 
No que diz respeito às necessidades técnicas, os TILS elencam: receber o material da aula com antecedência e ter melhor internet, ambiente e equipamentos de maior qualidade. Também mencionam a necessidade de ter glossários acadêmicos da instituição para facilitar a busca por termos/palavras utilizadas neste ambiente. Dentro desta observação, foi pontuado que a UFF criou uma plataforma para reunir glossários com este intuito, a Plataforma Libras Acadêmica/UFF ${ }^{4}$, lançada em 17 de março de 2021.

Dentre os recursos virtuais que podem contribuir, destacam: ter uma plataforma de sala de aula virtual na qual os TILS possam estar em uma sala, vendo um ao outro, dando apoio para aquele que está interpretando no momento, sem ser visto pelos demais alunos da sala; dentro desta plataforma ter um espaço específico para o TILS na tela que permite a direta correlação da tradução com algumas imagens que são apresentadas. Na ferramenta utilizada para as atividades síncronas, Google Meet, o TILS fica em qualquer lugar da tela como se fosse um aluno, isso não favorece a visualização do todo (apresentação do professor, rosto do professor e intérprete) pelo aluno surdo.

Gomes e Valadão (2020) afirmam que a troca/apoio entre os intérpretes é muito importante em virtude da ausência de alguns léxicos na língua de sinais, bem como pelo fato de os TILS não terem como dominar tantos e tão diversos temas quanto precisam interpretar. Essa interação é, portanto, recorrente entre os intérpretes, e sua impossibilidade no meio virtual é algo que traz prejuízos ao processo tradutório.

A DS, primeiramente, esclarece que não gosta do modelo de ensino remoto, que isso não a agrada e, em seguida elenca os aspectos positivos e negativos deste modelo. Dentre os positivos, temos:

1. de acordo com experiências em outras instituições onde as aulas foram ministradas totalmente em Libras, a aluna relata que foram perfeitas, sem a necessidade de intérpretes e, explorando a visualidade, tornou possível a compreensão da forma adequada;

2. poder trocar/interagir com os colegas de turma que sabem Libras ao término da aula ou de alguma reunião.

Dentre os pontos negativos, cita:

1. excesso de aulas por videoconferência sem intervalo durante a aula ou entre disciplinas diferentes;

2. excesso de uso da fala e de pessoas levantando a mão para interagir;

3. falta de conhecimento, por parte dos professores, das características das pessoas surdas: não conhecem o perfil deste público nem didáticas e metodologias que podem ser utilizadas;

4. excesso de textos com pouca explicação/explanação;

5. didática inadequada, extremamente expositiva, sem troca, sem interação, sem construção do conhecimento em conjunto;

6. falta de domínio do conteúdo pelos intérpretes;

7. imagem do TILS travada e os professores seguindo a aula sem atender ao pedido do surdo para aguardar a sincronização da aula com a tradução;

8. prejuízo no processo de aprendizagem.

A importância da presença do TILS no ambiente de ensino é evidenciada pela DS ao relatar que, com a interpretação, ela recebe a informação de forma mais “leve, mais confortável” (resposta da DS à questão 7), porque a leitura labial é muito cansativa, exige demais da sua atenção e envolve maior esforço, por vezes ocorrendo perda de informações. Ela afirma também que, quando, na universidade, não há presença de intérprete em uma disciplina, a solução é desistir da disciplina. Esta

\footnotetext{
4 PROEX Divulga o lançamento da plataforma Libras Acadêmica da UFF. 17 mar. 2021. http://www.uff.br/?q=events/proex-divulga-o-lancamento-daplataforma-libras-academica-uff.
} 
situação nos leva a refletir sobre o que Carl Rogers afirma sobre o processo de aprendizado: um novo conhecimento representa uma "ameaça" interna, pois o novo pressupõe o desmonte/desestruturação do conhecimento do aluno e o instiga a mudar seus conceitos. Há uma tendência a resistir à "ameaça" do novo conhecimento. Sendo assim, há a orientação em minimizar ou mesmo eliminar as "ameaças externas" (Zimring, 2010, p. 21).

Logo, usar a língua mais confortável ao aluno contribui para a assimilação mais fácil e efetiva do conhecimento. Isso vai ao encontro da percepção da DS quanto às aulas no modelo remoto, entendendo como proveitosas aquelas ministradas em sua língua de conforto. Nestas aulas, ela consegue interagir, estabelecer trocas, as discussões podem ocorrer, pois ela não está com a mente ocupada em tentar entender vários novos conceitos nem está com dúvidas sobre a explicação dada, podendo participar plenamente.

A troca com os pares é apontada por Almeida (2017) e por Vygotsky (1995) como estimulantes ao aprendizado e ao desenvolvimento cognitivo e cultural, portanto, este grupo de alunos com os quais ela pode interagir após os momentos formais são fundamentais tanto para o desenvolvimento pedagógico como para o psicológico do aluno. Quando não há pares que saibam a língua para promover esta troca, Almeida (2017) afirma que o TILS, embora não faça parte obrigatória da sua função, pode atuar dialogando. No entanto, isso dependerá do perfil do TILS e da sua disponibilidade.

O modelo remoto representa um desafio tanto para o docente quanto para o discente. Na percepção da DS, a adaptação a este modelo ocorreu lentamente para ambos; a didática e metodologia inadequada para este ambiente revelou-se danosa para ela. Considerar a individualidade do aluno pressupõe empatia (Zimring, 2010). Ao se colocar no lugar do outro, o professor passa a refletir sobre o esforço despendido pelo aluno para aprender o conteúdo ministrado a ele na forma que está sendo apresentado. A DS destaca que há uma grande quantidade de textos para os alunos lerem que nem sempre podem ser trabalhados durante as aulas síncronas em função da limitação do tempo disponível dos TILS. Com isso, o surdo tem dificuldades em compreender o conteúdo, pela falta da mediação dos TILS para palavras e conceitos não comuns ao discente surdo.

No ensino remoto, isso significa excesso de exposição à tela, excesso de textos para leitura, que resulta em mais exposição à tela. Estes dados encontrados sobre a atuação docente e as dificuldades enfrentadas pela DS nos remetem às características das metodologias utilizadas no processo de ensino dentro da modalidade de ensino remoto. A aula expositiva, com o professor falando por horas seguidas, foi apontada pela DS como algo cansativo para a vista; por outro lado, a adoção da Sala de Aula Invertida ${ }^{5}$, com o professor passando vários textos na plataforma de aula virtual e alguns vídeos do YouTube legendados antes da aula síncrona, para que o aluno possa discutir no decorrer da aula, também se mostrou frágil por não prever a necessidade de uma explanação/explicação do texto e/ou do vídeo para que o aluno possa, de fato, compreender e participar ativamente da proposta. Para melhor atender o aluno surdo, é importante que o material seja disponibilizado com a tradução para Libras e, caso isso não seja possível, haja um momento de releitura e explanação dos trechos e ideias principais tanto de textos quanto dos vídeos. Para sanar esta lacuna, a DS, por vezes, buscava o auxílio dos TILS para tirar as dúvidas sobre o material disponibilizado.

As Metodologias Ativas ${ }^{6}$, em que o aluno deve ser proativo, tomar decisões, estabelecer hipóteses, discutir soluções, também parecem falhar na promoção de acessibilidade, dentro do caso estudado, visto que as discussões realizadas pelos alunos ouvintes não sinalizantes eram diversas e, por vezes, a DS relata não conseguir participar da trocar por ter perdido

\footnotetext{
5 A Sala de Aula Invertida consiste em transformar a sala de aula em um espaço dinâmico e interativo em que o aluno previamente tem acesso ao material que será utilizado para que em sala de aula possam acontecer debates e discussões, enriquecendo o aprendizado. (Bergmann \& Sams, 2012; Schneiders, 2018).

${ }^{6}$ A Metodologia Ativa de Ensino tem como objetivo desenvolver habilidades nos alunos para que sejam proativos, criativos, autônomos, que se envolvam em atividades mais complexas, tomem decisões e avaliem os resultados. São caminhos para a construção de um conhecimento mais profundo, trabalhando competências socioemocionais e em novos cenários de práticas (Lidving \& Ulriksen, 2019).
} 
informações. O uso de uma modalidade linguística diferente, mediada somente por um TILS, prejudica a participação da DS de forma plena. O ideal seria que, em turmas com alunos surdos incluídos, a maioria dos participantes soubessem sinalizar, visto que o modelo de ensino remoto não oportuniza maior interação entre os alunos. Entendemos da dificuldade de tornar esse ideal em realidade, e reiteramos a importância das reuniões e trocas entre docentes e TILS para elaborar estratégias e adaptações que possam sanar esta lacuna.

Em alguns casos, há sobrecarga de trabalho por não haver intérprete para substituí-lo. A DS relata uma de suas experiências com outra instituição, em que só havia um intérprete para toda a aula; como solução foi definido um intervalo de 20 minutos a cada 30 minutos de aula. A atuação do TILS é extenuante por todo o trabalho cognitivo que envolve, de captar a informação apresentada, decodificar para a língua alvo, estabelecer estratégias para a melhor apresentação e fazer as correlações com o tema de forma que a interpretação/tradução seja fidedigna e clara (Woodcock \& Fischer, 2008).

\section{Considerações Finais}

A discussão sobre o processo de interpretação tendo como ponto de partida as perspectivas dos TILS e da DS dentro do curso de doutoramento propiciaram a reflexão e percepção de diversas falhas/lacunas na acessibilidade para o aluno surdo no ambiente virtual síncrono e assíncrono.

Verificamos que há uma dificuldade da própria universidade em proporcionar os profissionais qualificados para garantir a acessibilidade do aluno surdo, seja por questões burocráticas, seja por falta de pessoal formado para suprir a demanda. Também identificamos, por parte da universidade, uma carência na formação dos docentes, onde se faz necessário estratégias específicas para receber o aluno surdo, além da consciência de que o material didático e a avaliação devem ser feitos de maneira adequada à especificidade dos alunos. Acreditamos que a formação continuada, tanto dos TILS quanto dos docentes, seja essencial para sanar estas questões.

Observamos que a atuação do TILS traz maior contribuição ao desenvolvimento do aprendiz quando ele atua como mediador do conhecimento, não se restringindo somente a passar a informação, mas também buscando o contato com o discente surdo para esclarecer dúvidas e estabelecer o diálogo. Talvez deva ser criado o cargo de TILS Mediador, com regulamentação e atribuições específicas, para sanar esta falta.

O modelo de ensino remoto, embora tenha se revelado possível e facilitador em diversos aspectos como menor locomoção, maior alcance dos alunos e dos professores e diferentes formas de interação, ainda carece de aperfeiçoamento para garantir uma aprendizgem efetiva e inclusiva. Dentre os aperfeiçoamentos, podemos destacar as estratégias metodológicas e didáticas que prezam mais pelo visual, estabeleçam tempos de aula mais adequados e equilibrem a quantidade de conteúdo apresentado. Vale ressaltar a necessidade de garantir equipamentos de qualidade e conexão de internet adequada tanto para os TILS quanto para os docentes e discentes.

Pudemos observar que as metodologias de ensino utilizadas não contemplam a diversidade e a inclusão de todos aqueles que possuem especificidades e que devem ter as mesmas possibilidades de aprendizado que os demais. Qualquer metodologia que busque atender às demandas deste novo cenário mundial deve reconhecer a diversidade e a inclusão como elementos fundamentais.

\section{Referências}

Almeida, W. G. (2017). A guia-interpretação o processo de inclusão do indivíduo com surdocegueira. Educar em Revista, Curitiba, Brasil, 65, 167-181, jul./set. doi: https://doi.org/10.1590/0104-4060.49000.

Bergmann, J. \& Sams, A. (2012). Flip your classroom: Reach every student in every class every day. USA:ISTE. 
Brandão, C. R. (Org.). (1999). Repensando a pesquisa participante. 3 ed. São Paulo: Brasiliense.

Brasil. (2002). Lei No 10.436, de 24 de abril de 2002. Dispõe sobre a Língua Brasileira de Sinais - Libras e dá outras providências.

Brasil. (2005). Decreto ${ }^{\circ} 5626$, de 22 de dezembro de 2005. Regulamenta a Lei $\mathrm{n}^{\circ} 10.436$, de 24 de abril de 2002 e o art. 18 da Lei $\mathrm{n}^{\circ} 10.098$ de 19 de dezembro de 2000.

Brasil. (2010). Lei N 12. 319, de 61 de setembro de 2010. Regulamenta a profissão de Tradutor Intérprete da Língua Brasileira de Sinais - LIBRAS.

Brasil. (2015). Lei Nº 13.146, de 6 de julho de 2015. Institui a Lei Brasileira de Inclusão da Pessoa com Deficiência.

Brasil. (2020a). Portaria $\mathrm{N}^{\mathrm{o}}$ 343, de 17 de março de 2020. Dispõe sobre a substituição das aulas presenciais por aulas em meios digitais enquanto durar a situação de pandemia do Novo Coronavírus - COVID-19. Ministério da Educação (MEC).

Brasil. (2020b). Portaria Nº 345, de 19 de março de 2020. Altera a Portaria MEC no 343, de 17 de março de 2020. Ministério da Educação (MEC).

Cordeiro, R. A. A. (2019). Sinal Datilológico em Libras. (Dissertação de mestrado) - Universidade Federal de Santa Catarina, Florianópolis, SC: UFSC. https://repositorio.ufsc.br/handle/123456789/214836.

Eisenhardt, K. M. (1989). Building theories from case study research. Academy of Management Review. New York, NY, 14(4), 532-550 https://bityli.com/FQDS4.

Glat, R. \& Pletsch, M. D. (2017). O papel da universidade frente as políticas públicas para educação inclusiva. Benjamin Constant, (29). https://bit.ly/3iyiSpG.

Gomes, E. A. \& Valadão, M. N. (2020). Tradução e interpretação educacional de Libras-Língua Portuguesa no ensino superior: desdobramentos de uma atuação. Trab. linguist. apl., Campinas, 59(1), 601-622, abr. doi: https://doi.org/10.1590/010318136376115912020.

Guarinello, A. C., Santana, A. P., Figueiredo, L. C. \& Massi, G. (2008). Intérprete da Língua Brasileira de Sinais na cidade de Curitiba. Revista Brasileira de Educação Especial, Marília, Jan.-Abr. 14(1), 63-74. doi: https://doi.org/10.1590/S1413-65382008000100006.

Instituto Brasileiro de Estatística e Geografia (IBGE). (2010). Censo 2010. http://www.ibge.gov.br/censo/.

Instituto Nacional de Estudos e Pesquisas Educacionais Anísio Teixeira (INEP). (2019). Censo da Educação Superior 2019. https://www.gov.br/inep/pt-br.

Kelman, C. A. (2005). Os diferentes papéis do professor intérprete. Espaço: Informativo Técnico-Científico, Rio de Janeiro, 24, 25-30.

Lacerda, C. B. F. de. \& Gurdel, T. M. do A. (2011). Perfil de tradutores-intérpretes de Libras (TILS) que atuam no ensino superior no Brasil. Rev. bras. educ. espec., Marília, 17(3), 481-496, dez. doi: https://doi.org/10.1590/S1413-65382011000300009.

Lidving, K. \& Ulriksen, L. (2019). Different, Difficult, and Local: A Review of Interdisciplinary Teaching Activities. The Review of Higher Education, 43(2), 697-725.

Martins, O. B. (2003). Teoria e prática tutorial em educação a distância. Educar, Curitiba: Editora UFPR, 21, $153-171$.

Medeiros Portella, S., Goudinho, L. da S., Ferreira, A. T. S., Mendes, M. C. B., Vale, M. R. M. dos S., Oliveira, A. F. de, Leite, E. A., Silva Junior, E. dos S., Silva, M. J. da, Fausto, I. R. de S., Pinto, S. C. C. da S., \& Braz, R. M. M. (2021). The biological basis of deafness. Research, Society and Development, 10(10), e16101018656. https://doi.org/10.33448/rsd-v10i10.18656

Minayo, M. C. de S. (2001). Pesquisa social: teoria, método e criatividade. Petrópolis: Vozes.

Ministério Público do Trabalho (MPT). (2020). Nota Técnica - GT COVID 19 - 11/2020 de 17 jun. 2020. Nota Técnica para a atuação do Ministério Público do Trabalho na defesa da saúde e demais direitos fundamentais de professoras e professores quanto ao trabalho por meio de plataformas virtuais e/ou em home office durante o período da pandemia da doença infecciosa COVID-19. Brasília, DF. https://bit.ly/3iyQNii.

Mousinho, R., Schmid, E., Mesquita, F, Pereira, J., Mendes, L., Sholl, R. \& Nóbrega, V. (2010). Mediação escolar e inclusão: revisão, dicas e reflexões. Rev. Psicopedagogia, 27(82), 92-108. https://shortest.link/Xqv .

Napier, J. (2002). University interpreting: linguistic issues for consideration. Journal of Deaf Studies and Deaf Education, 7(4), 281 - 301. doi: https://doi.org/10.1093/deafed/7.4.281.

Nascimento, R. \& Segala, R. (2018). O feedback em vídeo como dispositivo de avaliação formativa em atividades didáticas de tradução audiovisual da Libras. Revista Translatio, 15, 102-121, jun. Porto Alegre. https://bit.ly/356AGjJ.

Paiva, V. L. M. O. (2007). As habilidades orais nas narrativas de aprendizagem. Trabalhos em Linguística Aplicada, 46(2), 165-179.

Prodanov, C. C. \& Freitas, E. C. de F. (2013). Metodologia do Trabalho Científico [recurso eletrônico]: métodos e técnicas da pesquisa e do trabalho acadêmico. 2 ed. Nova Hamburgo: Feevale.

Conselho de Ensino, Pesquisa e Extensão (PROPPI). (2020). Resolução N. ${ }^{\circ}$ 157/2020. Dispõe sobre critérios para o planejamento e execução de Atividades Acadêmicas dos cursos de Pós-Graduação Stricto Sensu e Lato Sensu no período da pandemia, e dá outras providências. https://bit.ly/3vf3MYO.

Quadros, R. M. de \& Stumpf, M. R. (2014). Letras Libras EaD. In: QUADROS, Ronice M. (Org.). Letras Libras: ontem, hoje e amanhã. Florianópolis: SC, Ed. UFSC, 9-36. https://bityli.com/3x7vp. 
Research, Society and Development, v. 10, n. 12, e79101220196, 2021

(CC BY 4.0) | ISSN 2525-3409 | DOI: http://dx.doi.org/10.33448/rsd-v10i12.20196

Schneiders, L. A. (2018). O método da sala de aula invertida (flipped classroom). Lajeado: Ed. da Univates. https://bit.ly/3zfphvY.

Vygotsky, L. S. (1995). Fundamentos de defectologia: Obras completas. Havana: Editorial Pueblo y Educación.

Woodcock, K. \& Fischer, S. L. (2008). Occupational Health and Safety for Sign Language Interpreters. Toronto ON: Ryerson University. https://bit.ly/3gn1u4F.

Xavier, K. S. (2012). O lugar do intérprete educacional nos processos de escolarização do aluno surdo. (Dissertação de mestrado) - Universidade Federal do Espírito Santo, Vitória: UFES. https://bit.ly/3cAgPxD.

Yin, R. K. (2003). Case Study Research: design and methods. Applied Social Research Methods. v. 5, Thousand Oaks, California: Sage Publications. https://url.gratis/n8g2g.

Zimring, F. (2010). Carl Rogers. Recife: Fundação Joaquim Nabuco, Ed.: Massangana. 